\title{
Epidemiology of the epilepsies
}

\author{
J W A S Sander, S D Shorvon
}

\section{Methodological issues}

DIAGNOSTIC ACCURACY AND CASE FINDING Accurate diagnostic and case ascertainment methods are a prerequisite for epidemiological research. In epilepsy, a common problem is diagnostic accuracy as it can be diagnosed only by taking a history of the index event or by chance observation of a seizure. ${ }^{1}$ The diagnosis is fundamentally a discretionary judgement which depends on the skill and experience of the physician and the quality of witness information available. ${ }^{2}$ Common sources of confusion are syncope or psychogenic attacks. ${ }^{1-6}$ As many as $10 \%-20 \%$ of cases referred to specialised epilepsy units with seemingly intractable seizures do not have epilepsy. ${ }^{1-2} 4-6 \mathrm{Up}$ to $30 \%$ of patients developing epilepsy will eventually be classified as having chronic epilepsy. ${ }^{7-8}$ The inclusion of patients with non-epileptic attacks in the "chronic epilepsy" group may artificially inflate the proportion of chronic cases. ${ }^{8} \mathrm{By}$ contrast, many patients with epilepsy have the condition for some time before the correct diagnosis is achieved. ${ }^{1910}$ Most studies lack clear and reproducible diagnostic definitions, a recent exception being one in Ecuador. ${ }^{11} 12$

Case ascertainment also poses problems in epilepsy. Some patients with seizures never seek medical attention either through concealment, denial, or ignorance. ${ }^{13-14}$ It is likely, therefore, that field studies miss patients unless sensitive screening techniques for all epileptic phenomena are included in the case ascertainment. This has not yet been achieved. It could be argued that patients not presenting to a medical agency should not be considered a problem. This may hold sway in clinical practice but in epidemiology it is important that all cases are included. ${ }^{15}$

The commonest method of case ascertainment is a retrospective review of medical notes, for seizures, antiepileptic drugs (AEDs), EEG, or a diagnostic coding. ${ }^{1}$ There are major sources of inaccuracy and underreporting is common. The extent of this was shown by a study in Warsaw that found a prevalence rate of $5 \cdot 1 / 1000$ based on a survey of medical records alone which rose to $10 \cdot 4 / 1000$ in a sample of $0.5 \%$ of the community. ${ }^{13}$ Similarly, in Guam, incidence rates based on field surveys were twice as high as those based on medical records only. ${ }^{16}$
Studies employing record reviews have covered total populations, ${ }^{17-23}$ a random sample, ${ }^{13-24}$ or selected groups such as sick funds policy holders, ${ }^{25}$ army draftees, ${ }^{26}$ hospital attenders, ${ }^{27-28}$ school children, ${ }^{29-31}$ government employees, ${ }^{32}$ those with learning disabilities, ${ }^{33}$ or general practitioners' lists. ${ }^{34-37}$ A second approach has been the use of a register of cases but unless precautions are taken, these may present the same diagnostic problems as a review of existing records. ${ }^{9839}$ An advantage of a register set up for research purposes is that the methodology may be planned in advance. ${ }^{1}$

An epidemiological approach that does not rely on prior diagnosis is to carry out a community survey with a sensitive and specific screening questionnaire. ${ }^{40}$ This strategy works for tonic clonic seizures and other seizures with florid clinical symptomatology. For other seizure types, however, this may not be accurate as a pragmatic screening instrument for these seizures has not yet been designed. An attempt to design such a questionnaire had to be abandoned due to the low specificity of questions relating to absence and myoclonic seizures. ${ }^{40}$

Community surveys using a screening questionnaire have been carried out in various locations. ${ }^{121341-66}$ Entire populations, random samples, or subgroups have been selected. Such surveys depend crucially on the adequacy of the screening methods and these are difficult to design. It is important to reach a balance between sensitivity and specificity, which has not yet been satisfactorily achieved. ${ }^{40} \mathrm{~A}$ screening questionnaire and its validation are not easily transferable between different populations due to cultural and social influences and must in all cases be piloted and validated for each population.

\section{CLASSIFICATION}

Current classifications of epilepsy are unsatisfactory for epidemiological purposes. Cases are categorised according to seizure type and broad aetiological categories. The agreed seizure type classification incorporates EEG data in a way which is inadequately defined. ${ }^{67}$ Even when presented with extensive EEG recordings and clinical data, specialists often fail to agree on classification ${ }^{68}$ and disagreements concerning seizure classification are often voiced. ${ }^{69} 70$ The use of EEG in field sur- 
veys is often impractical, in which case the seizure type classification is inapplicable. ${ }^{71}$ Many published studies, however, have reported the use of this system, without using EEG data and others have used modified versions of the scheme which do not require EEG data. ${ }^{11}$

Epileptic seizures may be a manifestation of many disease entities and an aetiological classification is of great interest. The relative frequency of different causes may vary in different locations. Cysticercosis is, for instance, the commonest identified cause of epilepsy in parts of Latin America, ${ }^{72-74}$ but is virtually unknown in Europe. Most studies that have attempted to classify aetiologies have done so in broad aetiological groupings (symptomatic and cryptogenic or idiopathic). Few cross sectional studies have attempted to classify patients in terms of more strictly defined aetiologies. Reasons for this may be logistical as in many locations complex investigations are impractical. The use of the terms idiopathic epilepsy and cryptogenic epilepsy is a particular source of confusion. Idiopathic epilepsy is used by some authors to refer to the primary generalised epilepsies which have a genetic component with strictly defined clinical and EEG findings, ${ }^{75}$ but by others to refer to any case in which aetiology has not been established. This may make comparisons impossible, as most of the cryptogenic epilepsies differ in many respects from primary generalised epilepsy.

An international classification of epilepsies and epileptic syndromes has been proposed by the International League Against Epilepsy (ILAE).$^{76}$ This scheme, which is perhaps appropriate for use in tertiary referral centres, is difficult to apply in a field study or in retrospective surveys. Probably as a result of this it has seldom been used in any large population study. ${ }^{77}$ The Commission of Epidemiology and Prognosis of the ILAE in their recent guidelines for epidemiological studies on epilepsy offers a simplified version of the scheme and its use should be encouraged (see appendix). ${ }^{78}$ These guidelines define idiopathic epilepsies as being partial or generalised epileptic syndromes with particular clinical and EEG characteristics and a genetic component. The term cryptogenic epilepsies should be reserved for unprovoked partial or generalised seizures in which no factor associated with an increased risk of seizures has been identified and the term symptomatic for seizures associated with a known risk factor. ${ }^{78}$

Further difficulties arise concerning the definition of "epilepsy". The inclusion of single seizures, neonatal seizures, febrile seizures, acute symptomatic seizures, and inactive seizures may vary from study to study, and this may alter any rate by twofold or threefold. Another source of difficulty in prevalence studies is the patient with inactive epilepsy. It is now clear that in most people with epilepsy the seizures cease $e^{8357}$ but there is no agreement as to what duration of remission should occur before a patient is no longer designated as an active case. Some influential investiga- tors have taken the view that "once an epileptic always an epileptic", ${ }^{80}$ others have defined epilepsy as a condition in which a seizure has occurred in the preceding year, two years, or five years. Some investigators have taken treatment status into account, with patients in remission included if they are still taking drugs. Most reports have not considered this problem and it is often difficult to determine if reported rates, particularly of prevalence, are for the active condition or lifetime rates. In recognition of this problem the Commission's guidelines have also defined epilepsy in terms of activity. ${ }^{78}$ An active case is defined as a person with epilepsy who has had at least one seizure in the previous five years regardless of treatment. Inactive cases are defined as remission with treatment (a person with epilepsy with no seizures for more than five years and receiving treatment at the time of ascertainment) or remission without treatment (a person with epilepsy with no seizures for more than five years and not receiving treatment at the time of ascertainment).

\section{Geographic distribution \\ INCIDENCE}

Most of the incidence studies have been retrospective and carried out in the developed world. To date no prospective general population based study of the incidence of epileptic syndromes has been reported. There have, however, been a few clinic based studies of the incidence rates of specific syndromes-for instance, photosensitive epilepsy. ${ }^{81}$

Case ascertainment has usually been carried out from medical records or from the hospital clinic, as, for instance, in the studies from Nigata City, Japan, ${ }^{82}$ Iceland, ${ }^{17}$ Guam, ${ }^{16}$ Warsaw, ${ }^{13}$ Copparo, and Italy, ${ }^{21}$ but some have covered the whole population of an area, as in Umea, Sweden. ${ }^{83}$ Some investigations were augmented by a medical re-examination. ${ }^{13} 1784$ In the Guam ${ }^{16}$ and Warsaw studies, ${ }^{13}$ a representative household sample was also included. The studies from Rochester, Minnesota and Aarhus, Denmark, have used a retrospective research register. ${ }^{93839}$ In five studies from the developing world a community based house to house survey was used and incidence rates derived from patients whose seizures started in the year before the survey. Two of these studies were in Ecuador ${ }^{1255}$ and the others were in China, ${ }^{58}$ Chile, $^{63}$ and Tanzania. ${ }^{64}$ Studies from groups of general practitioners have been carried out in the United Kingdom ${ }^{34} 3785$ and they have used the number of patients registered in each practice as denominators instead of the more usual census figures. A particular problem in these investigations is the wide variation from practice to practice, suggesting that some general practitioners may have been more assiduous in their registration than others.

The annual incidence rates reported vary between $11 / 100000$ in Norway ${ }^{18}$ to $230 /$ 100000 in Ecuador, ${ }^{55}$ although most lie between 40 and 70/100 000 (table 1). The highest figures are from populations in developing countries ${ }^{12563}$ and this has been a con- 
Table 1 Published incidence and prevalence rates of epilepsy in the general population in different countries

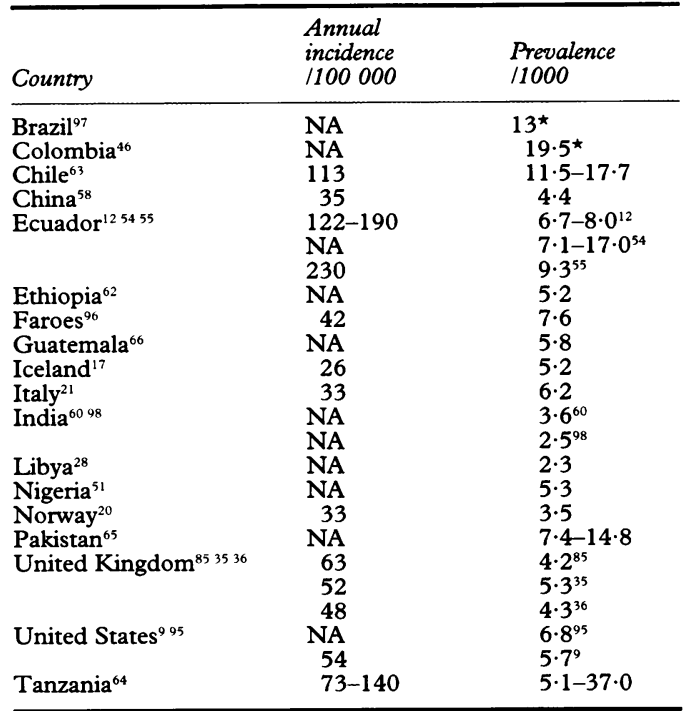

${ }^{\star}$ Lifetime prevalence.

sistent finding: almost all studies coming from such countries have reported incidence rates of over 100/100 000 whereas those from the developed world were usually between 40 and $70 / 100000$. In the developed world the classic studies of incidence are those from Rochester, Minnesota based on the Mayo Clinic linkage system. ${ }^{938}$ These have assessed incidence from 1935 to 1984 . Age adjusted annual incidence rates varied between 40 and 50/100 000 and few changes were seen in overall rates although over time the incidence decreased in children and increased in elderly people. In the developing world a study from semirural Ecuador where meticulous care was taken with methodological issues, an annual incidence rate between 122 and $190 / 100000$ was reported. ${ }^{12}$

\section{PREVALENCE RATES}

As cross sectional data are more easily obtained there are many more studies of the prevalence of epileptic seizures than of incidence; studies have been carried out in more than 25 countries in all five continents. ${ }^{913}$ 16-21 31-32 34-36 42-52 54-57 60 63-66 82 86-102 Most studies giving data on incidence also report prevalence, and there are additional investigations, some of which have been restricted to selected populations such as army draftees, ${ }^{26}$ sick fund policy holders, ${ }^{25}$ mine workers, ${ }^{103}$ school children, ${ }^{4890104}$ elderly people, ${ }^{105}$ and birth cohorts of children. ${ }^{84} 106$

As with incidence rates, reported prevalence rates are also very variable and rates as high as $57 / 1000$ and as low as $1 \cdot 5 / 1000$ have been given for active epilepsy (table 1 ). The average lifetime prevalence rates reported in these studies is $18 \cdot 5 / 1000$ (range $2 \cdot 8-44 / 1000$ ) for children only and $10 \cdot 3 / 1000$ (range $1 \cdot 5-57$ / 1000 ) for all ages. The problems of case ascertainment have been largely ignored in some of these studies, and no doubt this is partially responsible for the 30 -fold range in prevalence rates. The importance of definition can be illustrated by the study of 6000 patients from one general practice in southern England, where a lifetime prevalence of $20 \cdot 3 / 1000$ was found for all cases (including single, recurrent, active, and inactive cases but excluding febrile seizures) and 17.0 for those with recurrent seizures only, 10.5 for those with active epilepsy (defined as a seizure in the previous two years) or on treatment, and 5.3/100 000 for those with active epilepsy only. ${ }^{35}$

In relatively unselected populations, most studies in both the developing and the developed world have found the point prevalence of active epilepsy to lie between 4 and 10/1000.91213172122 24 31 35-365160626566859596 For prevalence studies, case finding methods may be usefully combined, and the population investigated at both community and hospital levels by screening questionnaire and medical examination. Many investigations may have underestimated the prevalence of epilepsy, and even if single seizures, febrile convulsions, seizures with acute illnesses, neonatal seizures, and inactive epilepsy are excluded, rates for chronic epilepsy of around 5 to $10 / 1000$ are probably applicable to all general populations in both the developed and developing world.

There have been studies originating in developing countries which reported high prevalence rates for epilepsy. These were from Tanzania, ${ }^{87} 107$ Nigeria, ${ }^{50}$ Liberia, ${ }^{93}$ Chile, ${ }^{63}$ Brazil, ${ }^{108}$ and Panama. ${ }^{109}$ The last study reported the highest recorded prevalence rate, of 57/1000; this was a study of 337 tribesmen with a concomitant high incidence of febrile convulsion. One problem with these studies, however, is that they were mostly on a small scale and were of selected or isolated populations which may have had high rates of genetic or rare degenerative diseases or a high prevalence of parasitic diseases. ${ }^{8}$

Most large scale studies of populations in the developing world have reported overall prevalence rates for active epilepsy around or below 10/100012515860626566; some of these studies have, however, reported differential rates for urban and rural areas, usually with higher rates in the rural areas. ${ }^{12}{ }^{65}$ This is clearly illustrated in a study from southern Pakistan where a prevalence rate for active epilepsy of $9 \cdot 9 / 1000$ for the area as a whole was reported; in the rural areas this was $15 / 1000$ by contrast with $7 \cdot 4 / 1000$ in the urban population. ${ }^{65}$ Similarly, in Ecuador a minimum lifetime prevalence of $14 \cdot 3 / 1000$ was reported for an Andean region; corresponding values for the urban and rural areas were respectively $9 / 1000$ and $15 \cdot 4 / 1000 . .^{12}$ In this study the area surveyed was divided into two distinct subregions: an upper region situated $2500-3200 \mathrm{~m}$ above sea level and inhabited primarily by people of Amerindian background and the other a temperate region situated at $1500-2000 \mathrm{~m}$ above sea level and with a population of African extraction. The lifetime prevalence of epilepsy was much lower in the higher area than in the lower region $(11 \cdot 2 / 1000 v 24 \cdot 8 / 1000)$. Other studies have also reported differing prevalence rates from within study areas. In Tanzania, an overall prevalence rate of $10 / 1000$ was reported for a rural district consisting of 11 villages; 
rates varied among the villages and a prevalence range of 5 to $37 / 1000$ was found. ${ }^{64}$ The differences reported in these studies from Pakistan, Ecuador, and Tanzania seem unlikely to be attributable to differential case ascertainment between the region as each study used identical methods, study design, and diagnostic confirmation in each area. No clear aetiological reason for these variations in prevalence in contiguous geographic areas were identified. These differences are of great potential importance, for herein may lie a clue to aetiology and indeed they possibly provide the basis for the prevention of epilepsy in rural areas. Future epidemiological work should be carried out to identify the reasons for these pronounced differences, including studies of the prevalence and case-control studies of neurocysticercosis and other parasitic diseases in rural areas of developing countries.

\section{LIFETIME PREVALENCE}

Cumulative incidence or lifetime prevalence rates are much higher than the incidence or the prevalence of active epilepsy, and on the basis of available figures it is generally agreed that between $1.5 \%$ to $5 \%$ of any population will have non-febrile seizures at some time. ${ }^{891217353638398385108}$ This finding applies to patients in both the developed and the developing world where the incidence seems to be higher and where treatment with antiepileptic drugs is not usually available. From the difference between lifetime prevalence and the point prevalence of active epilepsy it is obvious that most patients developing epilepsy will cease to have seizures or will die. It is likely that in most patients with seizure disorders the condition remits: however, it is known that the epilepsies are associated with an increased mortality, particularly but not exclusively with symptomatic cases. ${ }^{110-113}$ Patients with chronic epilepsy seem to be particularly at risk but the impact of mortality on the prevalence of epilepsy and the extent to which the difference in lifetime and point prevalence rates is due to mortality has not yet been fully appraised. ${ }^{114-115}$

In the developed world the overall good prognosis for seizure control is now attributed mainly to the widespread and early use of antiepileptic drugs. ${ }^{8112}$ The suggestion has been made, however, that a significant number of patients developing an epileptic syndrome will enter a permanent remission regardless of treatment with drugs. ${ }^{8}$ Support for this proposition has come from analysis of epidemiological data arising from the developing world where despite the lack of antiepileptic drugs a significant number of patients enter long term remission. ${ }^{116}$ In addition, it is well recognised that a number of epileptic syndromes-for instance, benign rolandic epilepsy and benign familial neonatal convulsions-have an excellent outcome which is independent of drug treatment. ${ }^{12}$ This is an area that requires further work, because if this lack of effect of antiepileptic drugs on prognosis is true on a wider basis, a change in the routine management of epilepsy may be necessary. If patients with an inherently good prognosis for their epileptic syndrome could be identified at the onset of their condition, the option of no treatment or only very short courses (to avoid seizure related accidents and morbidity) could become clear alternatives. If by the same token inherently bad prognosis syndromes could be identified earlier, more aggressive management may limit the "progression" of the disorder.

\section{Demographic and secular trends}

Little attention has been directed to changes in epidemiological rates over time. In most studies, age specific incidence rates are bimodally distributed with the highest peak in the first decade, and within this decade in the first year of life. The rates fall in the second decade and remain low in early and mid-adult life only to increase in late life when the second peak occurs. This, however, might be changing as some interesting shifts have been seen recently. ${ }^{117}$ In south east England, the incidence of epilepsy in children declined from $152 / 100000$ in the period of 1974 to 1983 to $61 / 100000$ in the years from 1984 to 1993 while increasing in elderly people over the same period. ${ }^{36}$ Similarly, in Rochester, Minnesota, the incidence of seizure disorders has decreased in children over time whereas it increased in elderly people to a point that the highest peak is now seen in people over the age of $75 . .^{38}$ In Sweden, it has recently been reported that the highest incidence of epileptic seizures is now in people over the age of 65 $(139 / 100000 v$ overall incidence rate for epilepsy of 56/100 $000^{83}$ ). The United Kingdom National General Practice study of epilepsy, a study of incident cases, found that only a quarter of all cases recruited were under age 15 when over $40 \%$ of new cases in this age range would be expected if previous age specific incidence data are correct. In this study over a quarter of the patients identified were aged 60 years or over. ${ }^{10118}$ One other study has also recently reported changes in the prevalence of epilepsy in the same population over time: the prevalence of active epilepsy declined from $5 \cdot 3 / 1000$ in 1983 to $4 \cdot 3 / 100010$ years later. ${ }^{36}$ No clear explanation for these changes has yet been advanced. In children speculation has centred on the role of improved prenatal care and the adoption of healthier lifestyles by expectant mothers, leading to a decrease in defects in neuronal migration and to a reduction in the incidence of birth hypoxia. ${ }^{112}$ In elderly people it is presumed that an increase in life expectancy allied to cerebrovascular diseases is responsible for the increase. This seems paradoxical, however, as the incidence of cerebrovascular diseases has decreased in the community over the past two decades. ${ }^{38}$

\section{Clinical characteristics}

Many studies have reported that most patients have generalised seizures and proportions as high as $88 \%$ have been reported. ${ }^{58}$ This is, however, likely to be due to such methodological problems as described above. In studies in 
which particular care was taken with seizure classification and EEG was used, most patients had partial seizures with or without secondarily generalisation and this is also the experience of most tertiary referral centres. In Rochester, Minnesota $66 \%$ of the patients had partial seizures ${ }^{9}$ and in the Warsaw field study $65 \%$ of patients were reported to have had partial seizures. ${ }^{13}$ In the large populationbased Ecuadorian study, seizures were classified without the use of EEG, and half of the patients were reported to have had partial seizures. ${ }^{12}{ }^{13}$ In the United Kingdom National General Practice study of epilepsy, in which routine investigations were applied, $52 \%$ of patients had partial seizures, $39 \%$ generalised seizures, and the remaining were unclassifiable. ${ }^{10}$

In most studies, only two seizure types were common: tonic clonic convulsions and partial seizures with or without secondarily generalisation. Other seizure types-that is, generalised absence, tonic and atonic seizures, and myoclonic seizures-are uncommon. Generalised absence, for instance, is usually reported in less than $2 \%$ of patients. ${ }^{15}$ Although this is a seizure type known to all medical students and practitioners, it is rare in population terms. The patient presenting with an absence is much more likely to have partial seizures than true generalised absence attacks, although these are often confused. For the diagnosis of true generalised absence seizures, an EEG recording showing three per second spike and waves discharges is necessary. Some studies that have reported the presence of generalised absences did not include EEG as part of the methodology. ${ }^{15}$

The present scheme for seizure classification is unsatisfactory and not suitable for field studies, in which the use of EEG is not practical. The categorisation of seizure type is often difficult, and there seems to be little doubt that partial seizures are often underreported. Many so-called generalised seizures are secondarily generalised, and should be categorised as partial, and the detection of a partial onset may depend on the skill of the investigator or the extent of investigation. The studies showing the highest proportion of partial seizures are those in which medical services are the most complex. Thus although this classification has often been said to have been used in large scale surveys, the reported seizure classification should be viewed with caution. Another point to note is the almost complete absence of unclassified convulsions in published reports which purport to have used the international classification. In hospital practice about one third of cases are unclassifiable. ${ }^{1}$

Table 2 The frequency of epilepsy in a population of 100000 in a developed country

\begin{tabular}{lc}
\hline New cases of epilepsy each year (incidence) & $40-70$ \\
Cases of active epilepsy (prevalence) & $500-1000$ \\
Cases who ever had epilepsy & $2100-5000$ \\
Seizure frequency for those with active epilepsy: & \\
No seizures for more than 12 months & $230-460$ \\
Between 1 and 12 seizures/year & $165-330$ \\
Between 12-50 seizures/year & $65-130$ \\
More than 50 seizures/year & $40-80$ \\
\hline
\end{tabular}

Only a few population based studies have reported frequency and severity of seizures. Indeed, very often it is difficult to ascertain, from study reports, how many cases have qualified as cases only due to the use of antiepileptic drugs. In one large study on the use of antiepileptic drugs on prevalent cases in a developed country when this information was provided, $46 \%$ of patients were reported to have been seizure free in the previous year, $33 \%$ had between one and 12 seizures a year, and the remaining more than one seizure a month, $8 \%$ of whom had more than 50 seizures a year. ${ }^{119}$ In a prevalent population in a developing country where treatment with antiepileptic drugs was not generally available and only $15 \%$ of patients were using drugs at the time of the survey, $45 \%$ of patients were reported to have had less than 10 seizures before the survey, $14 \%$ between 10 and 100 seizures, and the remaining $26 \%$ more than 100 seizures. ${ }^{116}$

Table 2 gives the frequency of epilepsy in a population of 100000 in a developed country based on the figures discussed above.

\section{Risk factors, aetiologies, and the heterogeneity of the epilepsies}

RISK FACTORS AND AETIOLOGY

From hospital and clinic studies it is well known that the range of aetiologies in the epilepsies varies in different age groups and also according to geographic location. Congenital, developmental, and genetic conditions are associated with epilepsy in childhood, adolescence, and in young adults. In elderly people, cerebrovascular disease is common. Head trauma, sporadic CNS infection, and tumours may occur at any age although tumours are more likely over the age of 40 . In certain areas endemic infections that are associated with epileptic seizures are common. The aetiology of epilepsy may be multifactorial and an acquired condition may be more likely to occur if an inherited predisposition is present. ${ }^{2}$ The relative contributions of each of these potential causes for the aetiology of the epilepsies in the general population have, however, not yet been formally ascertained.

In most field investigations, a putative aetiology for the epilepsy was found in only about a quarter or a third of cases. In the Rochester study, ${ }^{9} 5 \%$ were due to head trauma, $5 \%$ to cerebrovascular diseases, $4 \%$ to brain tumour, $4 \%$ to congenital or genetic abnormalities, and $3 \%$ to infectious diseases, whereas in the study from Copparo (which has one of the highest percentages of cases with known aetiology) $20 \%$ were said to be secondary to perinatal injuries, $7 \%$ to head trauma, $5 \%$ to infective diseases, $4 \%$ to cerebrovascular diseases, and $2 \%$ to brain tumour; in $61 \%$ no cause was found. ${ }^{21}$ In Ecuador, no putative cause for the seizures was identified in at least $73 \%$ of the patients. ${ }^{12}$ Likely aetiologies were estimated in the remaining $27 \%$ of patients and these included birth trauma $(9 \%)$, head injury $(7 \%)$, neurocysticercosis (3\%), and cerebrovascular diseases (3\%). In the United Kingdom 
National General Practitioners' study of epilepsy, seizures were classified as idiopathic or cryptogenic in $72 \%$, remote symptomatic in $25 \%$, and the remaining $3 \%$ were associated with neurological deficits present at birth. ${ }^{10}$ The commonest putative aetiology in this study was cerebrovascular disease. Overall $16 \%$ of all patients had this as the cause of their epilepsy but it rose to $49 \%$ in the group older than 60 . A similar finding has been reported from Sweden: cerebrovascular diseases were responsible for $30 \%$ of all cases of epilepsy in adults, but this increased to $46 \%$ in those aged 60 or over. ${ }^{83}$

It is self evident that the more extensive the investigation, the more likely are aetiological factors to be identified. To what extent this would modify the findings of a large scale epidemiological investigation is uncertain. Brain MRI identifies a very much higher rate of positive causes in hospital based surveys but in field surveys or in retrospective record reviews it is inapplicable. ${ }^{120}$ Indeed no population based study of epilepsy with modern neuroimaging as part of the study design has yet been reported Because of this, the true incidence of symptomatic epilepsies in the general populations is unknown, and is likely to be much higher than that found in the epidemiological studies cited above. As yet, no epidemiological based study accurately describes the range of aetiologies of epilepsy. This deficiency urgently needs to be corrected and is a vital prerequisite to sensitive case-control investigations of relative risk.

Sex

Most reports show slightly higher rates in males than in females. ${ }^{1}$ The suggestion that this is due to a higher incidence of head trauma has never been formally confirmed, and the low overall incidence of post-traumatic epilepsy makes this unlikely. ${ }^{121} 122$ Syncope and psychogenic attacks are much more common in females than in males, and the potential for misdiagnosis in epilepsy in females is greater. ${ }^{4}$ Consultation rates from general practices in the United Kingdom, for instance, show that females consult their general practitioner for episodes of disturbed consciousness of any sort twice as often as males. ${ }^{123}$

\section{Race and socioeconomic status}

There are several small scale reports showing high rates in black African populations. ${ }^{50868793}$ In Ecuador, the prevalence of seizures was much higher in a population predominantly of African descent than in a neighbouring population made up mostly by Amerindians. ${ }^{12} \mathrm{~A}$ higher prevalence rate for Afroamericans than for white subjects was reported in two studies of American school children. ${ }^{27124}$ A similar finding was reported in adults from a census of neurological diseases in a biracial population of Copiah County in the south of the United States. ${ }^{95}$ Similarly, United States mortality data suggest that the prevalence of epilepsy in non-white subjects is twice that of white subjects in America. ${ }^{125} \mathrm{~A}$ lower standard of perinatal care might be relevant, and the infant mortality rates among the black population in America is twice that of the white population. ${ }^{27}{ }^{126}$ Data from other developed countries and also from developing countries suggest higher prevalence rates in the lower socioeconomic classes 17344663127 but no definitive evidence for this suggestion has yet been unveiled. Case-control studies to consider this issue are also needed.

\section{THE HETEROGENEITY OF THE EPILEPSIES}

A fundamental issue, often glossed over in the epidemiological literature, is that of the heterogeneity of the epilepsies. ${ }^{8}$ Many different conditions, with differing causes and outcomes, may express themselves solely by the occurrence of recurrent epileptic seizures. Epilepsy is a collection of syndromes and conditions rather than a single disease, but most studies have reported on "epilepsy" as a whole or according to seizure type rather than by any more meaningful classification. An analogy can be drawn with the anaemias. ${ }^{128}$ If the epidemiology of anaemia were studied as if it were a single disorder, it is unlikely that useful aetiological data would ever arise.

\section{The syndromes of idiopathic epilepsy}

Even the "idiopathic" epilepsies, which are often considered homogeneous, include conditions with differing incidence and outcome. ${ }^{112}$ Thus generalised absence epilepsy, epilepsy with generalised tonic clonic convulsions on awakening, and juvenile myoclonic epilepsy are all well recognised syndromes under the rubric of the generalised idiopathic epilepsies. These conditions probably have different genetic mechanisms and may have different natural histories. A 24-fold difference in the cumulative incidence of generalised absence epilepsy has been reported between populations in Sweden and Japan, perhaps due to genetic differences. ${ }^{15}$ These aetiologically important factors would be obscured by epidemiological studies that categorised them all under idiopathic epilepsy.

It is self evident but often overlooked that classification by seizure type alone is not sufficient to allow a classification by syndrome. Generalised tonic-clonic seizures are characteristic of many epileptic syndromes. Such seizures can occur in acute symptomatic epilepsy, generalised epilepsy, whether idiopathic or symptomatic, and in all forms of localisation related epilepsy. The clinical characteristics of partial seizures also disclose little of aetiological or prognostic value. Seizures represent an expression of an underlying pathology, the cause of which is not disclosed in the phenomenology of the symptom. Epidemiological studies have, however, typically relied heavily on seizure characteristics as the key epilepsy variable.

Many epilepsy syndromes can only be diagnosed with the benefit of several years of follow up. Cross sectional studies will inevitably misclassify a significant number of cases. Studies done before access to modern investigation techniques do not reflect current thinking about the aetiology of epilepsy. The same 
also applies to field studies, particularly in developing countries, in which even EEG is often not practical.

\section{The need for case-control studies to investigate aetiology}

Studies have suggested that there are geographic differences in the incidence of epilepsy, with a higher incidence in the developing world. It is often implied that infections of the CNS are partly responsible for this increased incidence and this might well be true as many agents that infect the CNS are associated with both acute symptomatic seizures and seizures in the aftermath of infection. ${ }^{129130}$ Often, studies from the developing world link a high prevalence of some local infectious disease with epilepsy but most of these studies lack sufficient controls to confirm conclusively that the infections are the underlying cause. In Ecuador, Peru, Brazil, and Mexico for instance, neurocysticercosis is prevalent in attenders of neurological clinics, many of whom may have epilepsy. ${ }^{734129-134}$ Postmortem and other studies suggest that asymptomatic cysticercosis is also common. ${ }^{129} 135$ What is unknown, however, is the prevalence of epilepsy in all people who harbour cysticerci in their brain. No adequate large scale study of neurocysticercosis, on a population basis, has ever been carried out to ascertain attributable risk. Other parasitic disorders such as malaria, 129130136137 schistosomiasis, ${ }^{138}$ paragonimiasis, ${ }^{129130136}$ or American trypanosomia$\operatorname{sis}^{63129139}$ have also been implicated as risk factors for subsequent epilepsy, but again this has not yet been substantiated. Another possible explanation for the finding of high prevalence rates in geographically isolated clusters, would be that this is due to genetically determined syndromes, ${ }^{8}$ but this also lacks confirmation.

Another important area of uncertainty is the role of neuronal migration disorders and other developmental abnormalities of the cerebral cortex in the aetiology of the epilepsies in the general population in both developed and developing countries. These are now well established as associated with chronic epilepsy in hospital attenders. ${ }^{140141}$ It is, however, not known what the prevalence of these conditions is in the population at large to enable an estimation of relative risk. By the same token, the finding of hippocampal sclerosis in patients with chronic partial epilepsy is associated with a history of febrile convulsion between the ages of 3 months and 5 years in over two thirds of the cases. ${ }^{142}$ Epilepsy, however, develops in less than $3 \%$ of children who experience a febrile convulsion with no previous neurological abnormalities and the risk factors for this are known. ${ }^{124142}$ It is still not known how common hippocampal sclerosis is in the general population or even among those who as youngsters experienced febrile convulsions but did not subsequently develop chronic epilepsy.

\section{Syndromic classification}

Two difficulties can be foreseen with a "syndromic approach" to the neuroepidemiology of the epilepsies. Firstly, the present syndromic classification is provisional. Recent advances in neuroimaging and neurogenetics are likely to identify further syndromes. For example, familial autosomal dominant frontal lobe epilepsy recently became characterised clinically, and shortly thereafter was linked to a specific genetic cause in some families. ${ }^{143}$ Other new disorders include the milder forms of neuronal migration disorders associated with epilepsy. ${ }^{140141}$ Secondly, there are questions that epidemiology in its present form cannot answer. For example, the reason why, in pathologically defined conditions, the response to treatment and final outcome is not always the same. This seems to indicate that factors other than gross pathology influence outcome. Cavernous angiomas, for instance, cause epilepsy in less than $70 \%$ of patients identified. ${ }^{144}$ Why do some patients with lesions in similar locations develop epilepsy and others do not? Furthermore, some who develop seizures respond to drug treatment, whereas others develop intractable epilepsy. The risk of epilepsy after severe non-penetrating head injury is about $20 \%$ at five years; some respond to drug treatment whereas others develop intractable epilepsy. ${ }^{121}$ There is anecdotal evidence that some people with epilepsy of temporal lobe type associated with hippocampal sclerosis respond favourably to certain antiepileptic drugs whereas others fail to respond to any drug. Thus presently "aetiologies" are not the sole determinant of outcome and response to treatment and unknown factors must exist. Current epidemiological studies are likely to fail to define completely the epileptic substrate. Further research at a neurobiological level is required before progress can be made. For any future research to have an impact it must also take into account the advances in neurogenetics and neuroimaging that so far have not been used to any extent in epidemiological work on the epilepsies.

\section{Conclusion}

Little is known about the true epidemiology of the different epileptic syndromes in the general population, as definitive studies are lacking. However, data based on seizure types suggest that the epilepsies are common, with an incidence between 40 and 200/100000 depending on geographic location. Despite this high incidence the overall prevalence lies between $0.5 \%-1 \%$ of the general population. It may be more common in specific age groups - that is, children and elderly peopleand in particular, geographic locations for genetic or environmental reasons. Changes in the age-specific incidence may be occurring with a shift to the older age groups. Those who develop epilepsy, not complicated by an underlying neurological disorder, have a good prognosis for full seizure control, although the full impact of mortality on the outcome of the epilepsies in the general population has not yet been fully assessed.

To extend our knowledge in this area future studies need to be large scale, general popula- 
tion based prospective incidence studies of the different epileptic syndromes with comprehensive case ascertainment, accurate diagnosis, and sound aetiological assignment. Cohorts of patients so identified should then be prospectively followed up to determine accurately the overall prognosis for seizure control and mortality, in tandem with analytical case-control studies to quantify aetiological risk factors. Further cross sectional studies are unlikely to be helpful. Specific questions that require investigation include the quantification of possible geographic differences in the incidence and the relative contribution of various aetiologies to the difference, the cause of possible changes in the age specific incidence, and accurate syndrome specific incidence rates. In addition, further studies to delineate the range of epileptic syndromes should be strongly encouraged.

We are grateful to Drs M F O'Donoghue, O C Cockerell, N Bharucha, and J Duncan for discussions and comments on the concepts discussed in this review.

Appendix: ILAE guidelines for epidemiological studies (adapted from ${ }^{78}$ )

(1) Definitions

EPILEPTIC SEIZURE

A clinical manifestation presumed to result from an abnormal and excessive discharge of a set of neurons in the brain. The clinical manifestation consists of sudden and transitory abnormal phenomena which may include alterations of consciousness, motor sensory, autonomic, or psychic events, perceived by the patient or an observer.

\section{EPILEPSY}

A condition characterised by recurrent (two or more) epileptic seizures, unprovoked by any immediate identified cause. Multiple seizures occurring in a 24 hour period are considered a single event. An episode of status epilepticus is considered a single event. Those who have had only febrile seizures or only neonatal seizures as herein defined are excluded from this category.

STATUS EPILEPTICUS

A single epileptic seizure $>30$ minutes in duration or a series of epileptic seizures during which function is not regained between ictal events in a $>30$ minute period.

\section{"ACTIVE EPILEPSY"}

A prevalent case of active epilepsy is defined as a person with epilepsy who has had at least one epileptic seizure in the previous five years, regardless of antiepileptic drug treatment. A case under treatment is someone with the diagnosis of epilepsy receiving (or having received) antiepileptic drugs on prevalence day.

\section{EPILEPSY IN REMISSION WITH TREATMENT}

A prevalent case of epilepsy with no seizures for five or more years and receiving antiepileptic drugs at the time of ascertainment.

EPILEPSY IN REMISSION WITHOUT TREATMENT

A prevalent case of epilepsy with no seizures for five or more years and not receiving antiepileptic drugs at the time of ascertainment.

SINGLE OR ISOLATED SEIZURE

One or more epileptic seizures occurring in a 24 hour period.

FEBRILE SEIZURE

An epileptic seizure as herein defined, occurring in childhood after age 1 month associated with a febrile illness not caused by an infection of the CNS, without previous neonatal seizures or a previous unprovoked seizure, and not meeting criteria for other acute symptomatic seizures.

NEONATAL SEIZURE

An epileptic seizure as herein defined occurring in the first 4 weeks of life.

FEBRILE SEIZURE WITH NEONATAL SEIZURE

One or more neonatal seizures in a child who has also experienced one or more febrile seizures as herein defined.

\section{NON-EPILEPTIC EVENTS}

Clinical manifestations presumed to be unrelated to an abnormal and excessive discharge of a set of neurons of the brain, including: (a) disturbances in the brain function (vertigo or dizziness, syncope, sleep and movement disorders, transient global amnesia, migraine, enuresis), and (b) pseudoseizures (non-epileptic sudden behavioural episodes presumed to be of psychogenic origin; these may coexist with true epileptic seizures).

\section{(2) Seizure type classification}

GENERALISED SEIZURES

A seizure is considered generalised when clinical symptomatology provides no indication of an anatomical localisation and no clinical evidence of focal onset. When possible, three main seizures subtypes may be categorised:

- Generalised convulsive seizures with predominantly tonic, clonic, or tonico-clonic features

- Generalised nonconvulsive seizures represented by absence seizure

- Myoclonic seizures.

In patients who have experienced several types of generalised seizure each seizure type must be categorised.

PARTIAL SEIZURES

A seizure should be classified as partial when there is evidence of a clinical partial onset, regardless of whether the seizure is secondarily generalised. The first clinical signs of a seizure ("the aura"), have a highly localising value and result from the anatomical or functional neuronal activation of part of one hemisphere.

- When alertness and ability to interact appropriately with the environment are maintained, the seizure is classified as a simple partial seizure.

- When impairment of consciousness, amnesia, or confusion during or after a seizure is reported, the seizure is classified as a complex partial seizure.

- When a seizure becomes secondarily generalised, the seizure is classified as partial seizure, secondarily generalised (simple or complex)

- When the distinction between simple and complex partial seizure cannot be made from information provided by history and medical records, the seizure is classified as partial epileptic seizure of unknown type.

- When a patient has several types of partial seizure, each should be separately categorised.

MULTIPLE SEIZURE TYPE

When both generalised and partial seizures are associated, each type must be described.

UNCLASSIFIED SEIZURES

The term unclassified seizures should be used when it is impossible to classify seizures owing to lack of adequate information.

\section{(3) Aetiology and risk factors}

Epileptic seizures and the epilepsies may be a manifestation of many cerebral or systemic diseases. The first step in categorisation of seizures should be based on the presence or absence of a presumed acute precipitating insult, which will permit distinction into provoked 
or unprovoked seizures. Single or recurrent unprovoked seizures may belong to two possible categories: symptomatic seizures, or epilepsies and seizures or epilepsies of unknown cause.

SYMPTOMATIC SEIZURES OR EPILEPSIES

These are considered to be the consequence of a known or suspected cerebral dysfunction.

Provoked seizures (acute symptomatic seizures)

Seizure(s) occurring in close temporal association with an acute systemic, metabolic, or toxic insult or in association with an acute CNS insult (infection, stroke, cranial trauma, intracerebral haemorrhage, or acute alcohol intoxication or withdrawal). They are often isolated epileptic events associated with acute conditions, but may also be recurrent seizures or even status epilepticus when the acute conditions recur-for example in alcohol withdrawal seizures.

\section{Unprovoked seizures}

Seizures may occur in relation to a well demonstrated antecedent condition, substantially increasing the risk for epileptic seizures. Two major subgroups may be categorised:

- Remote symptomatic unprovoked seizures owing to conditions resulting in a static encephalopathy. Such cases are patients with epilepsy subsequent to an insult of the CNS, such as infection, cerebral trauma, or cerebrovascular disease, which are generally presumed to result in a non-progressive (static) lesion.

- Symptomatic unprovoked seizures owing to progressive CNS disorders.

UNPROVOKED SEIZURES OF UNKNOWN AETIOLOGY Cases of unprovoked seizures for which no clear antecedent aetiology can be detected. If possible, these cases can be further classified into the following subheadings:

\section{Idiopathic epilepsies}

The term idiopathic is used here as defined by the $\mathrm{ILAE}^{76}$ and must be reserved for certain partial or generalised epileptic syndromes with particular clinical characteristics and with specific EEG findings, and should not be used to refer to epilepsy or seizures without obvious cause.

\section{Cryptogenic epilepsies}

The term cryptogenic is used to include partial or generalised unprovoked seizures or epilepsies in which no factor associated with increased risk of seizures has been identified. This group includes patients who do not conform to the criteria for the symptomatic or idiopathic categories. Whenever possible, the Commission on Epidemiology and Prognosis encourages use of the most recent ILAE Classification of Epilepsies and Epileptic Syndromes. ${ }^{76}$ Appropriate categorisation of individual cases may require use of state of the art technologies and procedures. In many settings in which epidemiological studies are conducted, in particular in field situations, all required information for proper classification of epileptic syndromes cannot be obtained.

1 Sander JWAS, Shorvon SD. Incidence and prevalence studies in epilepsy and their methodological problems: a
review. $¥$ Neurol Neurosurg Psychiatry 1987;50:829-39.

review. F Neurol Neurosurg Psychiatry 1987;50:829-39.
2 Nashef L. Definitions, aetiologies and diagnosis. In Shorvon SD, Dreifuss F, Fish D, Thomas D, eds. The treatment of epilepsy. Oxford: Blackwell, 1996:66-96.

3 Lempert T. Recognising syncope: piffalls and surprises. $\mathcal{F} R$ Soc Med 1996;89:372-5.

4 Duncan JS. Diagnosis-is it epilepsy? In: Duncan JS, Shorvon SD, Fish DR, eds. Clinical epilepsy. Edinburgh: Churchill Livingstone, 1995:1-24.

5 Trimble MR, Ring HA. Psychological and psychiatric aspects of epilepsy. In: Duncan JS, Shorvon SD, Fish
DR, eds. Clinical epilepsy. Edinburgh: Churchill Livingstone, 1995:321-48.

6 Lesser R. Psychogenic seizures. Neurology 1996;46: 1499-507.

7 Shorvon SD. Chronic epilepsy. BMF 1991;302:363-6.

8 Sander JWAS. Some aspect of the prognosis of the epilepsies. Epilepsia 1993;34:1007-16.
9 Hauser WA, Kurland LT. The epidemiology of epilepsy in Rochester, Minnesota 1935 through 1967. Epilepsia 1975;16:1-66.

10 Sander JWAS, Hart YM, Johnson AL, Shorvon SD. The National General Practice study of epilepsy: newly diagnosed seizures in a general population. Lancet 1990; 336:1267-71.

11 Placencia M, Suarez J, Crespo F, et al. A large scale study of epilepsy in Ecuador: methodological aspects. Neuroepidemiology 1992;11:71-84.

12 Placencia M, Shorvon SD, Paredes V, Bimos C, Sander JWAS, Cascante SM. Epileptic seizures in an Andean region of Ecuador: incidence and prevalence and regional variation. Brain 1992;115:771-82.

13 Zielinski JJ. Epidemiology and medico-social problems of epilepsy in Warsaw (Poland). Final report on research program No 19-P-58325-F-01. Warsaw: Psychoneurological Institute, 1974.

14 Beran RG, Michelazzi J, Hall L, Tsimnadis P, Loh S. False-negative response rate in epidemiological studies to define prevalence ratios of epilepsy. Neuroepidemiology to define prevale

15 Sander JWAS. The epidemiology and prognosis of typical absence seizures. In: Duncan JS, Panayiotopoulos CP, eds. The typical absences and related epileptic syndromes. Edinburgh: Churchill Livingstone, 1994:135-41.

16 Stanhope JM, Brody JA, Brink E. Convulsions among the Chamorro people of Guam, Mariana Island. $A m \mathcal{F}$ Epidemiol 1972;95:292-8.

17 Gudmundsson G. Epilepsy in Iceland. Acta Neurol Scand 1966;43:S-25.

18 Krohn W. A study of epilepsy in northern Norway, its frequency and character. Acta Psychiatr Scand 1961;36: S215-25.

19 Leibowitz U, Alter M. Epilepsy in Jerusalem, Israel. Epilepsia 1968;9:87-105.

20 de Graaf AS. Epidemiological aspects of epilepsia in northern Norway. Epilepsia 1974;15:291-9.

21 Granieri E, Rosati G, Tola R, et al. A descriptive study of epilepsy in the district of Copparo, Italy 1964-78. Epilepsia 1983;24:502-14.

22 Keranen T, Riekkinen PJ, Sillanpaa $M$. Incidence and prevalence of epilepsy in adults in Eastern Finland Epilepsia 1989;30:413-21.

23 Maremmani C, Rossi G, Bonucelli U, Murri L Descriptive epidemiological study of epileptic syndromes in a district of North-west Tuscany, Italy. Epilepsia 1991;32:294-8.

24 Brewis M, Poskanzer D, Rolland C, et al. Neurological diseases in an English city. Acta Neurol Scand 1966; $43(\mathrm{~S}-24): 1-89$.

25 Wajsbort J, Haral N, Alfandary I. A study of the epidemiology of chronic epilepsy in northern Israel. Epilepsia ology of chron

26 Jallon P. Evaluation du taux de prevalence de l'epilepsie dans un centre de selection de l'armee. Rev Neurol (Paris) 1991;147:319-22.

27 Shamansky S, Glaser G. Socio-economic characteristics of childhood seizure disorders in the New Haven area an epidemiological study. Epilepsia 1979;20:457-74.

28 Sridharan R, Radhakrishnan K, Ashok PP, Mousa ME. Epidemiological and clinical study of epilepsy in Benghazi, Libya. Epilepsia 1986;27:60-5.

29 Cooper JE. Epilepsy in a longitudinal survey of 5000 children. $B M \mathcal{F}$ 1965;1:1020-2.

30 Costeff $\mathrm{H}$. Convulsions in childhood: their natural history and indications for treatment. $N$ Engl $f$ Med 1965; and indication

31 Cavazzuti GB. Epidemiology of different types of epilepsy in school age children of Modena, Italy. Epilepsia 1980;21:57-62.

32 Olivares L. Epilepsy in Mexico: a population study. In: Milton A, Hauser WA, eds. The Epidemiology of epilepsy: $a$ workshop. Washington: DHEW, 1972. NINDS Monograph No 14.

33 Forsgren L, Edvinsson S, Blomquist HK, Heijbel J, Sidenvall $R$. Epilepsy in a population of mentally retarded children and adults. Epilepsy Res 1990;6: 234-48.

34 Pond D, Bidwell B, Stein L. A survey of 14 general practices. Psychiatria, Neurologia, Neurochirurgia 1960;63: 217-36.

35 Goodridge DMG, Shorvon SD. Epilepsy in a population of 6000. BMF 1983;287:641-7.

36 Cockerell OC, Eckle I, Goodridge DMG, Sander JWAS Shorvon SD. Epilepsy in a population of 6000 re-examined: secular trends in first attendance rates, prevalence, ined: secular trends in first attendance rates, prevalence, and progen.

37 Cockerell OC, Sander JWAS, Brodie D, Goodridge DGM, Shorvon SD. Neurological conditions in a defined population: the results of a pilot study in two general practices. Neuroepidemiology 1996;15:73-82.

38 Hauser AW, Annegers JF, Kurland LT. Incidence of epilepsy and unprovoked seizures in Rochester, Minnesota 1935-1984. Epilepsia 1993;34:453-68.

39 Juul-Jensen P, Foldspang A. Natural history of epileptic seizures. Epilepsia 1983;24:391-4.

40 Placencia M, Sander JWAS, Shorvon SD, Ellison RH, Suarez S, Cascante SM. Validation of a screening questionnaire for the detection of epileptic seizures in epidemiological studies. Brain 1992;115:783-94.

41 Lessell S, Torres JM, Kurland LT. Seizure disorders in a Guamanian village. Arch Neurol 1962;7:37-44. 
42 Mathai KV, Dunn DP, Kurland LT, Reeder FA Convulsive disorders in the Mariana Islands. Epilepsia 1968;9:77-85.

43 Rose SW, Penry JK, Markush RE, Radloff LA, Putnam PL. Prevalence of epilepsy in children. Epilepsia 1973 14:133-52.

44 Rowan J, Hyman HH. The prevalence of epilepsy in large heterogeneous urban population (The Bronx NY, 8 January 1975). Trans Am Neurol Assoc 1976;101: 281-3.

45 Meighan SS, Queener L, Weitman M. Prevalence of epilepsy in children of Multnomah County, Oregon Epilepsia 1976;17:245-56.

46 Gomez JG, Arciniegas E, Torres J. Prevalence of epilepsy in Bogota, Colombia. Neurology 1978;28:90-5.

47 Chiofalo N, Kirschbaum EP, Fuentes A, Cordero M Madsen J. Prevalence of epilepsy in children of Melipilla, Chile. Epilepsia 1979;20:261-6.

48 Gutierrez H, Rubio F, Escobedo F, Heron J. Prevalencia de epilepsia en ninos de edad escolar de una comunidad urbana de la Ciudad de Mexico. Gaceta Medica Mexicana 1980;116:497-501.

49 Beran RG, Hall L, Pesce A, et al. Population prevalence of epilepsy in Sydney, Australia. Neuroepidemiology

50 Osuntokun BO, Schoenberg BS, Nottidge VA, et al. Research protocol for measuring the prevalence of neurological disorders in developing countries. Results of a pilot study in Nigeria. Neuroepidemiology 1982;1: $143-53$.

51 Osuntokun BO, Adeuja AOG, Nottidge VA, et al. Prevalence of the epilepsies in Nigerian Africans: a community-based study. Epilepsia 1987;28:272-9.

52 Garcia-Pedroza F, Rubio-Donnadieu F, Garcia-Ramos G, et al. Prevalence of epilepsy in children: Tlalpan Mexico City, Mexico. Neuroepidemiology 1983;2:16-23.

53 Proano J. Preliminary results of the neuroepidemiological study in Quiroga, Equador. Community Neurology (Quito) 1984;1:11-2.

54 Cruz M, Ruales J, Bossano F, et al. Estudio Neuroepidemiologicos en el Ecuador CIEN, Fundacion Eugenio

55 Placencia M, Silva C, Cordova M, et al. Prevalencia de enfermedades neurologicas en una comunidad rural andin (Cangahua). Informe final. Quito: CONACYT, 1984

56 Kaamugisha J, Feksi AT. Determining the prevalence of epilepsy in the semi-urban population of Nakuru, Kenya, comparing two independent methods not apparently used before in epilepsy studies. Neuroepidemiolog 1988;7:115-21.

57 Pradilla G, Pardo C, Puentes F, et al. Estudio neuroepidemiologico en Giron, Colombia. Comite de Neuroepidemiologia. Bucaramanga: Universidad Industrial de Santander, 1984.

$58 \mathrm{Li}$ SC, Schoenberg BS, Bolis CL, et al. Epidemiology of epilepsy in urban regions of the People's Republic of China Epilepsia 1985;26:391-4.

59 Carpio A, Morales J, Calle H, Tinoco L, Santillan F. Prevalencia de epilepsia en la parroquia Cumbe, Azuay, Ecuador. Revista del Instituto de Ciencias de Salud Universidade de Cuenca (Ecuador) 1986;1:10-31.

60 Bharucha NE, Bharucha EP, Bharucha AE, Bhishe AV, Schoenberg BS. Prevalence of epilepsy in the Parsi community of Bombay. Epilepsia 1988;29:111-5.

61 Bondestam S, Garssen J, Abdulwakil A. Prevalence and treatment of mental disorders and epilepsy in Zanzibar. Acta Psychiatr Scand 1990;81:327-31.

62 Tekle-Haimanot $\mathrm{R}$, Forsgren L, Abebe M, et al. Clinical and electroencephalographic characteristics of epilepsy in rural Ethiopia: a community-based study. Epilepsy Res 1990;7:230-9.

63 Lavados J, Germain L, Morales A, et al. A descriptive study of epilepsy in the district of El Salvador, Chile. Acta Neurol Scand 1992;85:249-56.

64 Rwiza HT, Kilonzo GP, Haule J, et al. Prevalence and incidence of epilepsy in Ulanga, a rural district: a community-based study. Epilepsia 1992;33:1051-6.

65 Aziz H, Ali SM, Frances P, Khan MI, Hasan KZ. Epilepsy in Pakistan: a population-based epidemiologcal study. Epilepsia 1994;35:950-8.

66 Mendizabal JE, Salguero LF. Prevalence of epilepsy in a rural community of Guatemala. Epilepsia 1996;37: 373-6.

67 Commission on classification and terminology of the International League of epilepsy. Proposal for revised clinical and electronception of epileptic seizures. Epilepsia 1981;22:489-501.

68 Lavy S, Carmon A, Yahr I. Assessment of clinical and electroencephalographic classification of epileptic patients in everyday neurological practice. Epilepsia patients in everyda

69 Shorvon SD. The spectrum of epileptic seizures and syndromes. In: Duncan JS, Shorvon SD, Fish DR, eds. dromes. In: Duncan JS, Shorvon SD, Fish DR, eds. Clinical epilepsy.

70 van Donselaar CA, Geerts AT, Meulstee J, Habbema JDF, Staal A. Reliability of the diagnosis of a first seizure. Neurology 1989.39:267-71.

71 Alter M, Masland RL, Kurtzke JF, Reed DM. Proposed definitions and classifications of epilepsy for epidemiological purposes. In: Alter M, Hauser WA, eds. The epidemiology of epilepsy: a workshop. Washingt
NINDS monograph; chapter 27, 1972:147-8.
72 Sotelo J, Guerrero V, Rubio F. Neurocysticercosis: a new classification based on inactive and active forms. Arch Intern Med 1985;145:442-5.

73 Alarcon G, Olivares L. Cisticercosis cerebral. Manifestaciones en un medio de alta prevalencia. Revista de Investigaciones Clinicas 1975;27:209-15.

74 Del Bruto OH, Santibanez R, Noboa CA, Aguirre R, Diaz E, Alarcon TA. Epilepsy due to neurocysticercosis: analysis of 203 patients. Neurology 1992;42:389-92.

75 Gastaut H, Gastaut JA, Gastaut JL, Roger J, Tassinari CA. Epilepsie Generalisee primarie. In: Lugaresi E CA. Epilepsie Generalisee primarie. In: Lugaresi E, Pazzaglia P, Tassinari CA, eds. Evolution and progn

76 Commission on classification and terminology of the International League of Epilepsy. Proposal for revised international classification of epilepsies, epileptic syndromes and related seizure disorders. Epilepsia 1989;30:389-99.

77 Manford M, Hart YM, Sander JWAS, Shorvon SD. The National General Practice study of epilepsy: the syndromic classification of the ILAE applied to epilepsy in a general population. Arch Neurol 1992;49:801-8.

78 Commission of Epidemiology and Prognosis. Guidelines for epidemiological studies on epilepsy. Epilepsia 1993; 34:592-6.

79 Annegers JF, Hauser WA, Elveback LR. Remission of seizures and relapse in patients with epilepsy. Epilepsy 1979;20:729-37.

80 Lennox W. Epilepsy and related disorders. London: Churchill, 1960

81 Quirk JA, Fish DR, Smith SJM, Sander JWAS, Shorvon SD, Allen PJ. Incidence of photosensitive epileptic seizures: a prospective national study. Electroencephalog Clin Neurophysiol 1995;95:260-7.

82 Sato $S$. The epidemiological and clinico-statistical study of epilepsy in Nigata City. Clinical Neurology (Tokyo) 1964;4:413-24.

83 Forsgren L, Bucht G, Eriksson S, Bergmark L. Incidence and clinical characterization of unprovoked seizures in adults-a prospective population-based study. Epilepsia 1996;37:224-9.

84 Miller FJW, Court SDM, Walton WS, Know EG. Growing up in Newcastle-upon-Tyne. A continuing study of
health and illness in young children with their families. health and illness in young children with

85 Crombie DL, Cross KW, Fry J, et al. A survey of the epilepsies in general practice. A report by the Research Committee of the College of General Practitioners. $B M \mathcal{F}$ 1960;ii:416-23.

86 Levy LF, Forbes JL, Parirenyatwa TS. Epilepsy in Africans. Central Africa fournal of Medicine 1964;10 241-9.

87 Jilek-Aall L. Epilepsy in the Wapogoro tribe in Tanganyka. Acta Psychiatr Scand 1965;41:57-86.

88 Dada T. Epilepsy in Lagos, Nigeria. African fournal of Medicine 1970;1:161-84.

89 Poskanzer DC. A house-to-house survey of a community for epilepsy. In: Milton A, Hauser WA, eds. The epidemiology of epilepsy: a workshop. Washington: DHEW. ology of epilepsy: a workshop. Washingt

90 Baumann RJ, Marx MB, Leonidakis MG. An estimate of the prevalence of epilepsy in a rural Appalachian population. Am $\mathcal{F}$ Epidemiol 1977;106:45-52.

91 Baumann R, Marx M, Leonidakis M. Epilepsy in rura Kentucky: prevalence in a population of school age children. Epilepsia 1978;19:75-80.

92 Pascual M, Pascual J, Rodriguez L, Rojas F, Tejeiros A. La epilepsia: estudio epidemiologico en una poblacion 37:811-21.

93 Goudsmit J, van der Waals FW, Gajdusek DC. Epilepsy in the Gbawein and Wroughbarth Clan of Gran Bassa County, Liberia: the endemic occurrence of "See-ee" in the native population. Neuropidemiology 1983;2:24-34.

94 Ponce $P$, Fernandez $R$, D'Souse C, et al. Estudio de prevalencia de transtomos neurologicos en Lezama. In: prevalencia de transtornos neurologicos en Lezama. In: Ponce P, ed. Estudios neuroepidemiologicos in Venezuela. Departamento de Enfermedades Neurologicas. Caracas:

95 Haerer AF, Anderson DW, Schoenberg BS. Prevalence and clinical features of epilepsy in a biracial United States population. Epilepsia 1986;27:66-75.

96 Joensen P. Prevalence, incidence and classification of epilepsy in the Faroes. Acta Neurol Scand 1986;74: 150-5.

97 Marino Jr R, Cukiert A, Pinho E. Epidemiological aspects of epilepsy in S Paulo, Brazil. In: Wolf $\mathbf{P}$, Dam $M$, Dreifuss FE, eds. Advances in epileptology-XVIth Epilepsy International Symposium. New York: Raven Press, 1987.

98 Koul R, Razdau S, Motta A. Prevalence and pattern of epilepsy (Lath/Mirgi/Laran) in rural Kashmir, India. Epilepsia 1988;29:116-22

99 Zuloaga L, Soto C, Jaramilo D. Prevalencia de epilepsia en la ciudad de Medellin. Boletin OPS 1988;104:331-4.

100 Tsuboi T. Prevalence and incidence of epilepsy in Tokyo. Epilepsia 1988;29:103-10.

101 Cowan valence of the epilepsies in children and adolescents. Epilepsia 1989;30:94-106.

102 Chiofalo N, Schoenberg BS, Kirschbaum A, et al. Estudios epidemiologicos de las enfermedades neurologicas en Santiago Metropolitano, Chile. Abstracts of th IVth Pan American Congress of Neuroepidemiology, 
Cartagena, Colombia, 1989:17-8.

103 Bird AV, Heinz HJ, Klintworth PG. Convulsive disorders in Bantu mine-workers. Epilepsia 1962;3:175-87.

104 Baumann RJ. Classification and population studies of epilepsy. In: Anderson VE, Hauser WA, Penry JK,
Singh CF, eds. Genetic basis of the epilepsies. New York: Raven Press, 1982:11-20.

105 Delacourt A, Breteler MMB, Meinardi H, Hauser WA, Hofman A. Prevalence of epilepsy in the elderly-the Hofman A. Prevalence of epilepsy in the

106 Van den Berg BJ, Yeruhalmy J. Studies on convulsive disorders in young children. 1. Incidence of febrile and orders in young children. 1. Incidence of febrile and Res $1969 ; 3: 298-304$

107 Jilek-Aall L, Jilek W, Miller JR. Clinical and genetic aspects of seizure disorders prevalent in an isolated African population. Epilepsia 1979;20:613-22.

108 Fernandez JG, Schmidt MI, Tozzi S, Sander JWAS. Prevalence of epilepsy: the Porto Alegre study. Epilepsia 1992;33(S3):132.

109 Gracia F, Lao SL, Castillo L, et al. Epidemiology of epilepsy in Guayami Indians from Boca del Toro Province, Republic of Panama Epilepsia 1990;31:718-23.

110 Hauser WA, Hesdorffer DC. Epilepsy: frequency, causes and consequences. Maryland: Demos Publications, 1990.

111 Nashef L, Sander JWAS, Shorvon SD. The mortality of epilepsy. In: Pedley TA, Meldrum BS, eds. Recent epilepsy. In: Pedley TA, Meldrum BS, eds. Recent
advances in epilepsy. Vol 6. Edinburgh: Churchill advances in epilepsy. Vo

112 Sander JWAS. The prognosis, morbidity and mortality of epilepsy. In: Duncan JS, Shorvon SD, Fish DR, eds. Clinical epilepsy. Edinburgh: Churchill Livingstone, 1995:300-20

113 Cockerell OC, Johnson AL, Sander JWAS, Shorvon SD. The mortality of early epilepsy: the results of a community based study. Lancet 1994;344:918-21.

114 Klenerman P, Sander JWAS, Shorvon SD. Mortality of epilepsy: a study in patients in long term residential care. F Neurol Neurosurg Psychiatry 1993;56:149-52.

115 Nashef L, Fish D, Sander JWAS, Shorvon SD. Incidence of sudden unexpected death in an out-patient cohort with epilepsy at a tertiary referral centre. $f$ Neurol with epilepsy at a tertiary referra
Neurosurg Psychiatry 1995;58:462-4

116 Placencia M, Sander JWAS, Roman M, et al. The characteristics of epilepsy in a largely untreated population in
rural Ecuador. 7 Neurol Neurosurg Psychiatry 1994;57: rural E

117 Sander JWAS, Hart YM, Johnson AL, Shorvon SD. Seizures in childhood: a prospective community based cohort study. Acta Neurol Scand 1990;82:S9

118 Sander JWAS, Cockerell OC, Hart YM, Shorvon SD. Is the incidence of epilepsy falling in the UK? Lancet 1993;342:874.

119 Hart YM, Shorvon SD. The nature of epilepsy in the general population. I. Characteristics of patients receiving medication for epilepsy. Epilepsy Res 1995;21:43-9.

$120 \mathrm{Li} \mathrm{LM}$, Fish DR, Sisodiya SM, Shorvon SD, Alsanjari N, Stevens JM. High resolution magnetic resonance imaging in adults with partial or secondary generalised ing in adults with partial or secondary generalised epilepsy attending a tertiary referta
Neurosurg Psychiatry 1995;59:384-7.

121 Annegers JF, Grabow JD, Groover RV, et al. Seizures after head trauma: a population study. Neurology 1980; after head

122 Jennett B. Epidemiology of head injury. $f$ Neurol Neurosurg Psychiatry 1996;60:362-9.

123 Morrell DC, Gage HG, Robinson NA. Symptoms in general practice. f $R$ Coll Gen Pract 1971;21:32-43.
124 Nelson KB, Ellenberg JH. Predictors of epilepsy in children who have experienced febrile seizures. $N$ Engl $f$ Med 1976;295:1029-33

125 Kurtzke JR. Mortality and morbidity data on epilepsy. In: Alter M, Hauser WA, eds. The epidemiology of epilepsy: a workshop. Wash

126 Wise PH, Kotelchuck M, Wilson ML, Mills M. Racial and socio-economic disparities in childhood mortality in Boston. N Engl f Med 1985;313:360-6.

127 National Health Survey. Prevalence of chronic conditions in the United States. Series 10 No 109 . Washington: the United States. Series 10 No

128 Walker MC, Sander JWAS. The impact of new antiepileptic drugs in the prognosis of epilepsy: seizure freedom should be the ultimate goal. Neurology 1996;46:912-4.

129 Bittencourt PRM, Gracia CM, Lorenzana P. Epilepsy and parasitosis of the central nervous system. In: Pedley TA, Meldrum BS, eds. Recent advances in epilepsy. Vol 3. Edinburgh: Churchill Livingstone, 1988:123-59.

130 Commission on Tropical diseases of the International League against Epilepsy. Relationship between epilepsy and tropical diseases. Epilepsia 1994;35:89-93.

131 Schenone H, Ramirez R, Rojas A. Aspectos epidemiologicos de la neurocistercercoses en Latino-America. Boletim Chileno de Parasitologia 1973;28:61-72.

132 Sakamoto A. Estudo clinico e prognostico das crises epilepticas que iniciam na infancia numa populacao brasileira. [Tese que iniciam na infancia numa populacao brasileira. TTese (Ribeirao Preto), 1985.

133 Arruda WO. Etiology of epilepsy. A prospective study of 200 cases. Arq Neuropsiquiat 1991;49:251-4.

134 Garcia HH, Gilman R, Martinez M, et al. Cysticercosis as a major cause of epilepsy in Peru. Lancet 1993;341: $197-200$.

135 Cruz ME, Barry M, Cruz R, et al. Prevalence of neurocysticercosis in an Andean community in Ecuador. Neuroepidemiology 1995;14:29.

136 Senanayake N, Roman G. Aetiological factors of epilepsy in the tropics. F Trop Geo Neurol 1991;1:69-80.

137 Senanayake N, Roman G. Epidemiology of epilepsy in the tropics. $\mathcal{F}$ Trop Geo Neurol 1992;2:610-9.

138 Pitella JEH, Lana MA. Brain involvement in hepatosplenic Schistosomiasis mansoni. Brain 1981; 104:621-32.

139 Jardim E, Takayanagui OM. Epilepsia e doenca de Chagas cronica. Arq Neuropsiquiat 1981;39:32-41.

140 Raymond AA, Fish DR, Stevens JM, Cook MJ, Sisodiya SM, Shorvon SD. Subependimal heterotopia: a distinct neuronal migration defect associated with epilepsy. $f$ Neurol Neurosurg Psychiatry 1994;57:1195-202.

141 Raymond AA, Fish DR, Stevens JM, Sisodiya SM, Shorvon SD. Abnormalities of gyration, heterotopias, focal cortical dysplasias, microdysgenesis, dysembryoplastic neuroepithelial tumour and dysgenesis of the archicortex in epilepsy. Clinical, electroencephalographic and neuroimaging features in 100 adult patients. Brain 1995;118:629-60.

142 Shorvon SD. Status epilepticus: its clinical features and treatment in children and adults. Cambridge: Cambridge University Press, 1994:304-5.

143 Scheffer IE, Bhatia KP, Lopes-Cendes I, et al. Autosomal dominant frontal lobe epilepsy misdiagnosed as sleep disorder. Lancet 1994;343:515-7.

144 Simard JM, Garcia-Bengochea F, Ballinger WE, Mickle JP, Quisling RG. Cavernous angioma: a review of 126 collected and 12 new clinical cases. Neurosurgery 1986; 18:162-72. 